\title{
Slik kan \\ ernæringsmessig risiko følges opp bedre
}

Et prosjekt på Rikshospitalet viste at sykepleierne tok mer ansvar i ernæringsarbeidet når de fikk undervisning om temaet, og når det ble innført nye rutiner.

Kristin Woldstad

Fagutviklingssykepleier

Nyre- og gastromedisinsk sengepost, Kreft-, kirurgi- og transplantasjonsklinikken, Oslo universitetssykehus

Maria Grahl Ingemundsen

Sykepleier

Oslo universitetssykehus, Rikshospitalet

Tine Lise Folvik

Sykepleier

Nyre- og gastromedisinsk sengepost, Avdeling for transplantasjonsmedisin, Oslo universitetssykehus, Rikshospitalet

Ellisiv Lærum-Onsager

Førsteamanuensis og sykepleier

Lovisenberg diakonale høgskole

Ernæring

Kartlegging

Underernæring

Dokumentasjon

Sykepleien 2020108 (82558) (e-82558)

DOI: 10.4220/Sykepleiens.2020.82558

Hovedbudskap 
Hensikten med kvalitetsforbedringsprosjektet var å vurdere om undervisning og innføring av nye ernæringsrutiner bidro til at sykepleierne tok mer ansvar i ernæringsarbeidet.

Prosjektet kan ha bidratt til at ernæring har fått større oppmerksomhet; sykepleierne tok mer ansvar for pasientens ernæringsstatus og iverksatte nødvendige tiltak. Trolig var bevisstgjøringen av sykepleiernes ernæringskunnskap og et styrket samarbeid med klinisk ernæringsfysiolog viktige resultater fra prosjektet.

En rekke studier viser at det er høy forekomst av risiko for underernæring og underernæring, såkalt ernæringsmessig risiko, blant pasienter på norske sykehus (1-3). En sentral del av god ernæringspraksis i spesialisthelsetjenesten er å identifisere ernæringsmessig risiko (4).

Når en slik risiko er identifisert, kan individuell behandling iverksettes. Studier indikerer at tidlig ernæringsintervensjon reduserer komplikasjoner, sykehusoppholdets lengde, reinnleggelser, dødelighet og kostnader i forbindelse med sykehusopphold (5-6).

Ernæringsarbeid er et tverrfaglig anliggende (5), der sykepleiere har en sentral rolle. Det er imidlertid identifisert en rekke barrierer mot utøvelse av god ernæringspraksis. Blant annet rapporterer sykepleiere at de har lite kunnskap om ernæring, mangel på tid og mangelfull dokumentasjon av ernæring (2, 7-9).

\section{Kvalitetsforbedringsprosjektet startet}

I 2013 innførte Nyre- og gastromedisinsk sengepost ved Rikshospitalet, Oslo universitetssykehus (OUS) ernæringsscreening av alle inneliggende pasienter på bakgrunn av anbefalingene $i$ «Nasjonale faglige retningslinjer for forebygging og behandling av underernæring» (4).

Sengeposten mottar elektive pasienter og $\varnothing$-hjelpspasienter som har en akutt eller kronisk sykdom, enten i nyrene, leveren, bukspyttkjertelen, galleveiene eller mage- og tarmsystemet, primært i aldersgruppen 18-85 år.

Sykepleierne på posten screenet pasientene ved innkomsten og deretter en uke etter innleggelsen ved hjelp av Nutritional Risk Screening 2002 (NRS 2002). 
Flere av sykepleierne uttrykte at de hadde for lite kunnskap om effektive og individuelle ernæringstiltak til pasienter som var i ernæringsmessig risiko. I tillegg oppga de å være usikre på sin egen rolle i ernæringsarbeidet. Vi erfarte at den ukentlige screeningen av pasientene ofte uteble på sengeposten.

På bakgrunn av disse erfaringene iverksatte vi et kvalitetsforbedringsprosjekt. Hensikten var å vurdere hvorvidt $\varnothing \mathrm{kt}$ kompetanse i form av undervisning og innføring av nye ernæringsrutiner ville bidra til at sykepleierne tok mer ansvar for å iverksette tiltak for pasienter i ernæringsmessig risiko.

\section{Prosjektets innhold}

Prosjektet innebar at sykepleierne fikk undervisning i ernæring, og at vi innførte to nye rutiner på sengeposten: én fast screeningdag i uken og et eget ernæringsdokument $i$ pasientjournalene. Prosjektet hadde en varighet på 8,5 måneder og ble startet 18. oktober 2016 og avsluttet 30. juni 2017.

\section{Slik foregikk undervisningen}

Før prosjektet startet opp, fikk sykepleierne på sengeposten undervisning. Undervisningen var todelt og varte i 1,5 timer. Første delen av undervisningen omhandlet innføring i fast screeningdag, oppretting og bruk av det nye ernæringsdokumentet. To av prosjektmedarbeiderne som arbeidet klinisk på sengeposten, holdt denne undervisningen.

Den andre delen av undervisningen ble holdt av en klinisk ernæringsfysiolog (KEF), og følgende temaer ble belyst: juridiske rammer og retningslinjer, ernæringsmessig risiko for sengepostens pasienter, spesielle ernæringshensyn, sentrale ernæringstiltak og beregning av energibehov.

Undervisningen vektla hva som er sykepleiefaglige oppgaver i ernæringsarbeidet, og det ble utarbeidet retningslinjer for når KEF skulle kontaktes.

\section{Nye rutiner som vi innførte}

\section{Fast screeningdag}


Vi innførte rutinemessig screening med NRS 2002 av alle inneliggende pasienter én fast dag i uken. NRS 2002 består av en innledende screening og en hovedscreening. Innledende screening inkluderer fire spørsmål om kroppsmasseindeks (KMI <20,5), ufrivillig vekttap i løpet av de siste tre månedene, redusert matinntak den siste uken og alvorlig sykdom.

\section{«Vi innførte rutinemessig screening med NRS 2002 av alle inneliggende pasienter én fast dag i uken.»}

Hvis svaret er nei på alle fire spørsmålene, gjentas den innledende screeningen etter én uke hvis pasienten fortsatt er innlagt. Hvis svaret er ja på et av de fire spørsmålene, gjennomføres hovedscreening, og det foretas en grundigere vurdering av pasientens ernærings- og sykdomstilstand. Poengsummen går fra o til 7, og en skår >3 indikerer ernæringsmessig risiko (10).

\section{Ernæringsdokument i DIPS}

Vi utarbeidet et eget ernæringsdokument knyttet til pasientens behandlingsplan i det elektroniske journalsystemet DIPS. Dokumentet inkluderte ernæringsstatus fra de ukentlige screeningene med NRS 2002 fra innkomst til utskrivelse og tiltak som var satt i gang under innleggelsen.

Alle pasientene skulle få opprettet et ernæringsdokument innen 24 timer etter innleggelsen, fortrinnsvis ved innkomsten.

\section{Evaluering underveis i prosjektet}

Underveis i prosjektperioden foretok vi 14 evalueringer over 35 uker. Hensikten med jevnlige evalueringer var å kartlegge om sykepleierne fulgte opp de nye ernæringsrutinene, om ernæringsdokumentet var anvendbart, og om vi skulle gjøre noen forbedringer på dokumentasjonen underveis.

Evalueringene tok utgangspunkt i et oppsatt skjema vi hadde utarbeidet på forhånd. Ved hver evaluering gikk vi gjennom alle opprettede ernæringsdokumenter til pasienter som var inneliggende på sengeposten. 
Vi registrerte hvor mange inneliggende pasienter som hadde fått opprettet ernæringsdokument, samt tidspunktet for opprettelse. Vi så også på hvorvidt dokumentene var fullstendig utfylt, hvor mange pasienter med NRS 2002-skår $\geq 3$, og hvorvidt tiltak var iverksatt.

\section{Spørreskjema etter avsluttet prosjektperiode}

Vi sendte ut et spørreskjema til alle sykepleierne som hadde vært ansatt på sengeposten i prosjektperioden, inkludert de som hadde sluttet eller var i permisjon. Spørreskjemaet besto av to deler. Del 1 dreide seg om sykepleiernes opplevelse av ernæringsdokumentet, ernæringsscreening, kunnskap om ernæring og samarbeid med KEF og kjøkkenpersonalet.

Del 2 av spørreskjemaet var kun for sykepleierne som hadde deltatt i ernæringsundervisningen. Spørsmålene tok utgangspunkt i hvorvidt de opplevde undervisningen som nyttig med tanke på ny kunnskap, hvilken opplevelse de hadde av ansvaret, hvorvidt de iverksetter tiltak i større grad enn tidligere, og hvordan samarbeidet var med KEF.

Spørreskjemaet ble sendt ut til 25 sykepleiere, og svarprosenten var $76(n=19)$. Spørreskjemaet ble besvart anonymt, og vi foretok deskriptive analyser ved hjelp av Statistical Package for the Social Sciences (SPSS), versjon 24.

\section{Opprettet ernæringsdokument}

Resultatene fra de jevnlige evalueringene viste at 26 prosent $(\mathrm{n}=6)$ til 86,9 prosent $(\mathrm{n}=20)$ av pasientene som var innlagt på evalueringstidspunktet, hadde fått opprettet ernæringsdokument (tabell 1). Med unntak av én uke var mellom 46,1 prosent $(n=22)$ og 91,6 prosent $(n=25)$ av ernæringsdokumentene opprettet innen 24 timer.

Forekomsten av ernæringsmessig risiko (skår $\geq 3$ ) varierte mellom 20 og 67 prosent, og evalueringene viste at tiltak var igangsatt i de fleste tilfellene ved skår $\geq 3$. 
Tabell 1. Evaluering av nye rutiner fordelt på prosjektuker

\begin{tabular}{|c|c|c|c|c|c|c|c|c|c|c|c|c|c|c|}
\hline Variabler & $\begin{array}{l}\text { Uke } 3 \\
n=10\end{array}$ & $\begin{array}{l}\text { Uke } 5 \\
n=26\end{array}$ & $\begin{array}{l}\text { Uke } 7 \\
n=22\end{array}$ & $\begin{array}{l}\text { Uke } 9 \\
n=23\end{array}$ & $\begin{array}{l}\text { Uke } 13 \\
\mathrm{n}=22\end{array}$ & $\begin{array}{l}\text { Uke } 16 \\
n=21\end{array}$ & $\begin{array}{l}\text { Uke } 18 \\
n=24\end{array}$ & $\begin{array}{l}\text { Uke } 20 \\
n=25\end{array}$ & $\begin{array}{l}\text { Uke } 24 \\
n=26\end{array}$ & $\begin{array}{l}\text { Uke } 27 \\
\mathrm{n}=18\end{array}$ & $\begin{array}{l}\text { Uke } 29 \\
n=23\end{array}$ & $\begin{array}{l}\text { Uke } 31 \\
\mathrm{n}=18\end{array}$ & $\begin{array}{l}\text { Uke } 33 \\
n=25\end{array}$ & $\begin{array}{l}\text { Uke } 35 \\
n=24\end{array}$ \\
\hline \multicolumn{15}{|l|}{$\begin{array}{l}\text { Dokumentasjon } \\
\text { av ernæringsstatus }\end{array}$} \\
\hline $\begin{array}{l}\text { Opprettet ernærings- } \\
\text { dokument, } \mathrm{n}(\%)\end{array}$ & $\begin{array}{c}7 \\
(70)\end{array}$ & $\begin{array}{l}14 \\
(54)\end{array}$ & $\begin{array}{l}13 \\
(59)\end{array}$ & $\begin{array}{l}20 \\
(87)\end{array}$ & $\begin{array}{l}15 \\
(68)\end{array}$ & $\begin{array}{l}13 \\
(62)\end{array}$ & $\begin{array}{l}19 \\
(79)\end{array}$ & $\begin{array}{c}12 \\
(48)\end{array}$ & $\begin{array}{c}20 \\
(77)\end{array}$ & $\begin{array}{c}12 \\
(67)\end{array}$ & $\begin{array}{c}6 \\
(26)\end{array}$ & $\begin{array}{c}8 \\
(44)\end{array}$ & $\begin{array}{l}15 \\
(60)\end{array}$ & $\begin{array}{l}16 \\
(67)\end{array}$ \\
\hline $\begin{array}{l}\text { Opprettet ernærings- } \\
\text { dokument innen } \\
24 \text { timer, } n(\%)\end{array}$ & $\begin{array}{c}4 \\
(57)\end{array}$ & $\begin{array}{c}7 \\
(50)\end{array}$ & $\begin{array}{c}6 \\
(46)\end{array}$ & $\begin{array}{l}14 \\
(70)\end{array}$ & $\begin{array}{l}10 \\
(67)\end{array}$ & $\begin{array}{l}10 \\
(77)\end{array}$ & $\begin{array}{l}15 \\
(79)\end{array}$ & $\begin{array}{l}11 \\
(92)\end{array}$ & $\begin{array}{c}12 \\
(60)\end{array}$ & $\begin{array}{c}9 \\
(75)\end{array}$ & $\begin{array}{c}3 \\
(50)\end{array}$ & $\begin{array}{c}2 \\
(25)\end{array}$ & $\begin{array}{c}8 \\
(53)\end{array}$ & $\begin{array}{l}13 \\
(81)\end{array}$ \\
\hline \multicolumn{15}{|l|}{ Ernæringsscreening } \\
\hline $\begin{array}{l}\text { Skår >3, } \\
\text { n (\%) }\end{array}$ & $\begin{array}{c}3 \\
(43)\end{array}$ & $\begin{array}{c}4 \\
(28)\end{array}$ & $\begin{array}{c}8 \\
(61)\end{array}$ & $\begin{array}{c}5 \\
(28)\end{array}$ & $\begin{array}{c}3 \\
(20)\end{array}$ & $\begin{array}{c}6 \\
(46)\end{array}$ & $\begin{array}{c}4 \\
(21)\end{array}$ & $\begin{array}{c}7 \\
(58)\end{array}$ & $\begin{array}{c}6 \\
(30)\end{array}$ & $\begin{array}{c}5 \\
(41)\end{array}$ & $\stackrel{2}{2}$ & $\begin{array}{c}4 \\
(50)\end{array}$ & $\begin{array}{c}10 \\
(67)\end{array}$ & $\begin{array}{c}4 \\
(25)\end{array}$ \\
\hline $\begin{array}{l}\text { Iverksatt tiltak, } \\
\mathrm{n}(\%)\end{array}$ & $\begin{array}{c}3, \\
(100)\end{array}$ & $\begin{array}{c}4, \\
(100)\end{array}$ & $\begin{array}{c}5 \\
(62)\end{array}$ & $\begin{array}{c}4 \\
(80)\end{array}$ & $\begin{array}{c}3 \\
(100)\end{array}$ & $\begin{array}{c}5 \\
(8)\end{array}$ & $\begin{array}{c}3 \\
(75)\end{array}$ & $\begin{array}{c}5 \\
\text { (71) }\end{array}$ & $\begin{array}{c}4 \\
(67)\end{array}$ & $\begin{array}{c}4 \\
(80)\end{array}$ & $\begin{array}{c}2 \\
(100)\end{array}$ & $\begin{array}{c}4 \\
(100)\end{array}$ & $\begin{array}{c}10 \\
(100)\end{array}$ & $\begin{array}{c}4 \\
(100)\end{array}$ \\
\hline $\mathrm{n}=$ antall & & & & & & & & & & & & & & \\
\hline
\end{tabular}

\section{Ernæringsdokumentet ble ulikt mottatt}

Litt over halvparten av sykepleierne (68 prosent, $\mathrm{n}=13$ )

rapporterte at de ikke syntes det nye ernæringsdokumentet var ressurskrevende. Sykepleierne som opplevde dokumentet som ressurskrevende ( 26 prosent, $n=5$ ), oppga at årsaken var at det tok tid å fylle det ut.

En av respondentene skrev følgende i fritekstrubrikken: «Dersom pasienten har mange utfordringer i forhold til ernæring og allergier, kan det ta mye tid på en travel dagvakt.»

En annen påpekte følgende: «Noen ganger må man forklare pasienten spørsmålene, og noen ganger er pasienten usikker på egne data, og da kan det ta mye tid.»

De tre andre respondentene fremhevet at de i hovedsak syntes at ernæringsdokumentet var tidkrevende fordi det skulle fylles ut i innkomstsituasjonen. Flere av respondentene påpekte at ernæringsdokumentet kunne være nyttig når de hadde pasienter som var innlagt over tid. En skrev følgende: «Det [ernæringsdokumentet] er lurt når man har langliggere.»

De to sykepleierne som oppga at ernæringsdokumentet ikke var nyttig, påpekte at ernæringsdokumentet ikke ble anvendt. Det kom frem at litt over halvparten av sykepleierne (58 prosent, $\mathrm{n}=11$ ) opplevde dokumentet som delvis nyttig. Vi erfarte at dokumentet i liten grad ble benyttet aktivt av sykepleierne etter opprettelsen, noe som også ble kommentert i spørreskjemaet. 
I fritekstrubrikken oppga en av respondentene at årsaken var følgende: «Siden man oppretter [ernæringsdokumentet] på alle, blir det nok ikke brukt like hyppig som det burde». En annen skrev dette: «Vi iverksetter tiltak uavhengig av dokumentet, synes jeg.»

\section{Ernæringsarbeid er tverrfaglig}

Ernæringsarbeid er et tverrfaglig fagfelt, og sykepleiere må samarbeide med blant annet leger og KEF (10).

Prosjektlederen og prosjektdeltakerne var i jevnlig dialog med KEF om forbedringer av ernæringsrutinene.

Tilbakemeldingene fra KEF underveis i prosjektet var at ernæringsdokumentet var nyttig, og at det ble benyttet aktivt av KEF for å oppdatere seg på pasientenes ernæringsstatus.

I en studie kom det frem at hyppig bes $\varnothing \mathrm{k}$ av KEF på enheter der underernæring er vanlig, førte til betydelig større oppmerksomhet på ernæring hos sykepleiere og leger (11). Det ser ut til å samsvare med våre erfaringer.

Vi så at sykepleierne fikk større bevissthet om hva en ernæringsscreening innebærer, og begynte å henvise til KEF tidligere i forløpet. I tillegg registrerte vi tidlig i prosjektperioden at sykepleierne i mye større grad enn før prosjektstart diskuterte ulike tiltak hos pasienter i ernæringsmessig risiko.

\section{三 «Sykepleierne fikk større bevissthet om hva en ernæringsscreening innebærer.»}

KEF ga tilbakemelding om at hun opplevde at samarbeidet med sykepleierne etter oppstarten av prosjektet var tettere og mer hensiktsmessig. En utfordring var imidlertid at leger og andre tverrfaglige samarbeidspartnere ikke brukte ernæringsdokumentet i like stor grad som KEF.

Det medførte at sykepleierne måtte dobbeltføre og videreformidle muntlig til legene for at de skulle få informasjon om pasientens ernæringsstatus og iverksatte tiltak.

I en studie vektla sykepleierne at når data om ernæringsarbeid var lite etterspurt av legene, var det mindre motiverende å gjennomføre dokumentasjonen (8). Manglende tverrfaglig samarbeid er beskrevet i flere studier som en hemmende faktor for god ernæringspraksis (2). 


\section{Undervisningen økte kunnskapen}

Flesteparten av sykepleierne, uavhengig av om de hadde deltatt i undervisningen eller ikke, oppga at de hadde tilstrekkelig kunnskap om ernæring til å behandle sengepostens pasienter. De fleste (74 prosent, $\mathrm{n}=14$ ) oppga at det var ganske godt tilrettelagt på sengeposten for å iverksette ernæringstiltak, som for eksempel ønskekost.

Det var totalt ti sykepleiere som svarte på del $2 \mathrm{av}$ spørreskjemaet, og alle rapporterte at de syntes undervisningen var litt eller svært nyttig. De fleste oppga at de hadde fått litt ny kunnskap om ernæring gjennom undervisningen.

\section{$\equiv$ «Alle rapporterte at de syntes undervisningen var litt eller svært nyttig.»}

Over halvparten (67 prosent, $\mathrm{n}=8$ ) oppga at de i større grad opplevde å ha mer ansvar for pasientens ernæringsstatus, og at de i stor grad iverksatte ernæringstiltak til pasienter i ernæringsmessig risiko sammenliknet med før undervisningen.

Samtidig oppga 67 prosent $(n=8)$ at de kun hadde lært litt nytt om iverksetting av ernæringstiltak etter endt undervisning. Det at de fleste sykepleierne svarte at de kun lærte litt nytt i undervisningen med KEF, kan trolig skyldes at mange var nyutdannet og hadde mye kunnskap friskt i minne fra studiene, eller at det som ble lagt frem, var presentert tidligere på fagdager og fagm øter.

Undervisningen kan også ha bidratt til en bevisstgjøring hos sykepleierne, slik at de ble mer oppmerksom på hvilken kunnskap de innehadde, og hvordan de kunne bruke den. En studie som unders $\varnothing$ kte sykepleiernes kunnskap om ernæring og deres evne til å ta ansvar i ernæringsarbeidet før og etter et undervisningsopplegg, ser ut til å samsvare med våre resultater.

Det kom frem at sykepleiernes $\varnothing$ kte kunnskaper etter undervisningen førte til at de ble mer bevisst på sin egen rolle og tok mer ansvar for å sette i gang tiltak hos pasienter i ernæringsmessig risiko (12). I undervisningen tydeliggjorde KEF sykepleiernes eget ansvarsområde, noe som trolig bidro til at sykepleierne ble mer trygge på sin egen rolle $\mathrm{i}$ ernæringsarbeidet. 


\section{Forankring hos ledelsen og medarbeidere}

Informasjon og opplæring alene er sjelden tilstrekkelig for å lykkes med å etablere ny praksis. Faktorer som støtte fra ledelsen samt faglig kompetente og engasjerte medarbeidere som har tilstrekkelig tilgang på ressurser, er trolig avgjørende for å lykkes.

I en studie kom det frem at når sykepleielederen aktivt st $\varnothing$ tter ernæringsarbeidet, opplever sykepleierne det som positivt, og det medfører høyere screeningprosent (13). Prosjektet var helt fra starten av forankret i ledelsen, både i selve avdelingen og på sengeposten. Vi hadde jevnlige møter med ledelsen for å informere om prosjektets fremdrift og diskuterte problemstillinger som dukket opp underveis.

Det var trolig positivt for gjennomføringen av prosjektet at sykepleiere med gode kunnskaper om ernæring og som arbeidet klinisk, var med som prosjektmedarbeidere og pådrivere i implementeringen og underveis i prosjektet. Tilgjengelige ressurspersoner eller et team som har spesiell kunnskap innenfor ernæring, er fremhevet i flere studier som betydningsfullt for å forbedre ernæringsarbeidet (14-15).

\section{$\equiv$ ¿Prosjektet var helt fra starten av forankret i ledelsen.»}

Vårt inntrykk er at sykepleierne opplevde det som mindre belastende når påminnelse om screening kom fra en kollega, fordi det føltes mer som en kollegial «trenger du hjelp med noe»-holdning. Det er mulig at hvis påminnelsen hadde kommet fra ledelsen, ville sykepleierne opplevd det som en «streng» påminnelse om at de ikke hadde gjort jobben sin.

Ernæringsarbeidet ble på den måten mer et samarbeid enn et direkte krav fra ledelsen, spesielt i travle perioder. Underveis i prosjektet informerte vi sykepleierne om resultatene fra evalueringene, som for eksempel hvor mange prosent av pasientene som hadde fått opprettet ernæringsdokument.

«Ernæringsprosjektet» var også et eget punkt på personalmøter, slik at sykepleierne fikk mulighet til å komme med tilbakemelding. De jevnlige evalueringene, hvor vi på samme tidspunkt oppdaterte sykepleierne om status for prosjektet, ble samtidig en påminnelse om å foreta screening. 


\section{Referanser}

1. Tangvik RJ, Tell GS, Guttormsen AB, Eisman JA, Henriksen A, Nilsen RM, et al. Nutritional risk profile in a university hospital population. Clin Nutr. 2015;34(4):705-11.

2. Eide HD, Halvorsen K, Almendingen K. Barriers to nutritional care for the undernourished hospitalised elderly: perspectives of nurses. J Clin Nurs. 2015;24(5-6):696-706.

3. Jacobsen EL, Brovold T, Bergland A, Bye A. Prevalence of factors associated with malnutrition among acute geriatric patients in Norway: a cross-sectional study. BMJ Open. 2016;6(9):e-011512.

4. Helsedirektoratet. Nasjonale faglige retningslinjer for forebygging og behandling av underernæring. Oslo: Helsedirektoratet; 2013. IS-1580. Tilgjengelig fra: https://helsedirektoratet.no/retningslinjer/nasjonal-fagligretningslinje-for-forebygging-og-behandling-avunderernering (nedlastet 08.05.2020).

5. Tappenden KA, Quatrara B, Parkhurst ML, Malone AM, Fanjiang G, Ziegler TR. Critical role of nutrition in improving quality of care: an interdisciplinary call to action to address adult hospital malnutrition. J Parenter Enter Nutr. 2013;37(4):482-97.

6. Khalatbari-Soltari S, Marques-Vidal P. The economic cost of hospital malnutrition in Europe; a narrative review. Clin Nutr ESPEN. 2015;10(3):89-94.

7. Mowe M, Bosaeus I, Rasmussen HH, Kondrup J, Unosson $\mathrm{M}$, Rothenberg $\mathrm{E}$, et al. Insufficient nutritional knowledge among health care workers? Clin Nutr. 2008;27(2):196-202.

8. Juul HJ, Frich JC. Kartlegging av underernæring i sykehus: Hva hemmer og fremmer sykepleieres bruk av screeningverkt $\varnothing y$ for identifisering av ernæringsmessig risiko? Nordisk Sygeplejeforskning. 2013;3(2):77-89.

9. Kårstad KA, Olsen NR, Sygnestveit K, Jamtvedt G, Aarflot M, Tangvik RJ. Dokumentasjonen av ernæringspraksis i spesialisthelsetjenesten er mangelfull. Sykepleien Forskning. 2018;13(72857):e-72857. DOI: 10.4220/Sykepleienf.2018.72857 
10. Helsedirektoratet. Kosthåndboken - veileder i

ernæringsarbeid i helse- og omsorgstjenesten. Oslo:

Helsedirektoratet; 2016. IS-1972. Tilgjengelig

fra: https://www.helsedirektoratet.no/veiledere/kosthandboke

$\mathrm{n}$ (nedlastet 08.05.20).

11. Thoresen L, Rothenberg E, Beck AM, Irtun $\varnothing$. Doctors and nurses on wards with greater access to clinical dietitians have better focus on clinical nutrition. J Hum Nutr

Diet. 2008;21(3):239-47.

12. Bjerrum M, Tewes M, Pedersen P. Nurses' self-reported knowledge about and attitude to nutrition - before and after a training programme. Scand J Caring Sci. 2012;26(1):81-9.

13. Porter J, Raja R, Cant R, Aroni R. Exploring issues influencing the use of the Malnutrition Universal Screening Tool by nurses in two Australian hospitals. J Hum Nutr Diet. 2009;22(3):203-9.

14. Green SM, James EP. Barriers and facilitators to undertaking nutritional screening of patients: a systematic review. J Hum Nutr Diet. 2013;26(3):211-21.

15. Lindorff-Larsen K, Rasmussen HH, Kondrup J, Staun M, Ladefoged K, The Scandinavian Nutrition Group. Management and perception of hospital undernutrition. A positive change among Danish doctors and nurses. Clin Nutr. 2007;26(3):371-8. 